\title{
Load shedding in power system using the AHP algorithm and Artificial Neural Network
}

\author{
Le Thi Hong Nhung ${ }^{1}$, Hoang Thi Trang ${ }^{2}$, Trong Nghia Le ${ }^{1}$, Huy Anh Quyen ${ }^{1}$, \\ Trieu Tan Phung ${ }^{3}$
}

\author{
${ }^{1}$ Department of Faculty of electrical and Electronics Engineering, University of Technology and Education, Vietnam \\ ${ }^{2}$ Dong Nai Technology University, Vietnam \\ ${ }^{3}$ Cao Thang Technical College, Vietnam
}

Received: 06 Nov 2020; Received in revised form: 25 Nov 2020; Accepted: 06 Dec 2020; Available online: 12 Dec 2020 C2020 The Author(s). Published by Infogain Publication. This is an open access article under the CC BY license (https://creativecommons.org/licenses/by/4.0/).

\begin{abstract}
This paper proposes the load shedding method based on considering the load importance factor, primary frequency adjustment, secondary frequency adjustment and neuron network. Consideration the process of primary frequency control, secondary frequency control helps to reduce the amount of load shedding power and restore the system's frequency to the permissible range. The amount of shedding power of each load bus is distributed based on the load importance factor. Neuron network is applied to distribute load shedding strategies in the power system at different load levels. The experimental and simulated results on the IEEE 37- bus system present the frequency can restore to allowed range and reduce the damage compared to the traditional load shedding method using under frequency relay-UFLS.
\end{abstract}

Keywords-AHP, ANN, AHP algorithm, frequency control, load shedding.

\section{INTRODUCTION}

Frequency is an importance technical parameter in evaluating the power quality of the power system and it has to be maintained within specified limits to ensure stable operation of the grid. Therefore, the maintaining the frequency in specified limits is always the goal of the electrical system's designer and operator. When there is a generator failure in electrical system, the frequency will droop. When the corrective method cannot restore the frequency back to steady state, the load shedding is quick and necessary method to restore the system's frequency. In load shedding, it is necessary to rapidly devise a reasonable load shedding strategy in order to help the frequency restore to permissible values quickly. Previous researches on load shedding mainly focus on the solving the optimization the shedding power [1-3]. In fact, the important issue is in the bulk grid, the factors of load shedding position and time to recover the parameters of the system quickly and within the allowable range. Because there are a lots information need to be processed to find out which load needs to be shed, so that, many algorithms have been studied and applied. In [4], an improved model of Artificial Adaptive Neutral Network (AANN) is presented to enhance the reliability of the grid. In [5], the proposed load shedding method based on the fuzzy logic to combine the frequency and speed of frequency change of the electrical system. In [6], by using Particle Swarm Optimization (PSO) to support Fuzzy system in order to plan the load shedding strategy. These studies mainly focus on optimize the load shedding power under established operating mode conditions of the electrical system. However, due to the complexity of the grid, in case of the emergency operation, these methods have problems with amount of data, calculating time and the processing speed of the algorithm is relatively slow or passive load shedding after waiting for the frequency below the threshold. As a result, it has caused delays in the decision to load shedding. In addition, these studies only focus on single problems; it is the application of intelligent algorithms to solve the load shedding problem without combining with other problems, for example, the load shedding problem considers the load importance factor to reduce economic losses in an overall solution to restore the power system frequency. 
To overcome these above problems, this paper proposes the load shedding using neuron network is capable of quickly responding to the requirement of distributed load shedding control when there is a generator failure occurs causing frequency droop and load shedding must be processed in bulk system. In each case, the amount of shedding power is calculated taking into account the primary frequency control and secondary frequency control of the generator. These load shedding strategies have been pre-designed by using Analytic Hierarchy Process (AHP) algorithm, and rapidly help in making decisions to control load shedding process and reduce the economic loss.

The efficiency of the proposed method is tested on the IEEE 37- bus 9- generator power system. The results of the proposed method are compared with the underfrequency load shedding method (UFLS). The process of identifying and quickly distributing the load shedding strategy using the neuron network combined with the predesigned load shedding control based on the AHP algorithm has helped the frequency quickly restores to the nominal values and the restoring time of the frequency is faster than the traditional load shedding method.

\section{FREQUENCY CONTROL IN POWER SYSTEM AND AHP ALGORITHM}

\subsection{Arrange the shedding priority of the load units based on the importance factor}

The application of Analytic Hierarchy Process (AHP) algorithm [7] is proposed by T.L. Saaty with the idea of using expert knowledge to rank the objects in a system. This algorithm arranges the priority for load shedding of the load units through the following steps:

Step 1: Identify the Load Centre areas $\mathrm{LC}_{\mathrm{i}}$ and the load units $L_{j}$ in the power system diagram, this division of load centers is based on the criteria that the loads are close to each other or in the same load cluster.

Step 2: Set up a hierarchy model based on the Load Centre areas and load units identified in Step 1.

Step 3: Set up judgment matrix $\mathrm{LC}_{\mathrm{i}}$ and $\mathrm{L}_{\mathrm{j}}$ showing the importance factor of load centers and the importance factor among loads in the Load Centre together. The values of the components in the judgment matrix reflect the operational experience of the operating expert on the importance of the relationship between the pair of factors presented in equation (1), (2).

$$
\begin{aligned}
& L C=\left[\begin{array}{ccc}
\mathrm{w}_{\mathrm{K} 1} / \mathrm{w}_{\mathrm{K} 1} \mathrm{w}_{\mathrm{K} 1} / \mathrm{w}_{\mathrm{K} 2} & \ldots . . \mathrm{w}_{\mathrm{K} 1} / \mathrm{w}_{\mathrm{Km}} \\
\mathrm{w}_{\mathrm{K} 2} / \mathrm{w}_{\mathrm{K} 1} \mathrm{w}_{\mathrm{K} 2} / \mathrm{w}_{\mathrm{K} 2} \ldots . . \mathrm{w}_{\mathrm{K} 2} / \mathrm{w}_{\mathrm{Dm}} \\
\cdot \\
\mathrm{w}_{\mathrm{Kn}} / \mathrm{w}_{\mathrm{K} 1} \mathrm{w}_{\mathrm{Kn}} / \mathrm{w}_{\mathrm{K} 2} & \ldots . . \mathrm{w}_{\mathrm{Km}} / \mathrm{w}_{\mathrm{Km}}
\end{array}\right] \\
& L_{j}=\left[\begin{array}{c}
\mathrm{w}_{\mathrm{D} 1} / \mathrm{w}_{\mathrm{D} 1} \mathrm{w}_{\mathrm{D} 1} / \mathrm{w}_{\mathrm{D} 2} \ldots . . \mathrm{w}_{\mathrm{D} 1} / \mathrm{w}_{\mathrm{Dn}} \\
\mathrm{w}_{\mathrm{D} 2} / \mathrm{w}_{\mathrm{D} 1} \mathrm{w}_{\mathrm{D} 2} / \mathrm{w}_{\mathrm{D} 2} \ldots . . \mathrm{w}_{\mathrm{D} 2} / \mathrm{w}_{\mathrm{Dn}} \\
\cdot \\
\cdot \\
\mathrm{w}_{\mathrm{Dn}} / \mathrm{w}_{\mathrm{D} 1} \mathrm{w}_{\mathrm{Dn}} / \mathrm{w}_{\mathrm{D} 2} \ldots . . \mathrm{w}_{\mathrm{Dn}} / \mathrm{w}_{\mathrm{Dn}}
\end{array}\right]
\end{aligned}
$$

Where: $\mathrm{m}$ is the number of the Load Centre; $\mathrm{n}$ is the number of loads in a Load Centre; $\mathrm{W}_{\mathrm{Di}} / \mathrm{W}_{\mathrm{Dj}}$ describe the relative importance of the $i_{\text {th }}$ load compared to the $j_{\text {th }}$ load; $\mathrm{W}_{\mathrm{Ki}} / \mathrm{W}_{\mathrm{Kj}}$ describe the relative importance of the $\mathrm{i}_{\mathrm{th}}$ Load Centre compared to the $\mathrm{j}_{\text {th }}$ Load Centre. The value $\mathrm{W}_{\mathrm{Di}} / \mathrm{W}_{\mathrm{Dj}} ; \mathrm{W}_{\mathrm{ki}} / \mathrm{W}_{\mathrm{kj}}$ can be obtained from the experience of experts or system operators through the use of the 9scaling method.

If both loads A and B are equally important, then the scaling factor will be "1".

If load $\mathrm{A}$ is a bit more important than load $\mathrm{B}$, then the scaling factor of A to B will be "2".

If load A is slightly more important than load B, then the scaling factor of A to B will be "3".

If load $\mathrm{A}$ is relatively more important than load $\mathrm{B}$, then the scaling factor of A to B will be "4".

If load $\mathrm{A}$ is more important than load $\mathrm{B}$, then the scaling factor of A to B will be " 5 ".

If load $\mathrm{A}$ is relatively more important than load $\mathrm{B}$, then the scaling factor of A to B will be "6".

If load A is much more important than load B, then the scaling factor of A to B will be "7".

If load $\mathrm{A}$ is extremely relatively important compared to load B, then the scaling factor of A to B will be " 8 ".

If load A is extremely important compared to load B, then the scaling factor of A to B will be "9".

Step 4: Calculate the importance factor of the Load Centre areas together and the importance factor of the load units in the same load area on the basis of set up a judgment matrix. According to AHP principles, the importance factor of the load can be calculated through the calculation of the maximal eigenvalue and the corresponding eigenvector of the judgment matrix. The calculation steps using the root method are as follows:

- Multiply all elements of each row in the judgment matrix

$$
M_{i}=\prod_{i} X_{i j}, \mathrm{i}=1, \ldots, \mathrm{n} ; \mathrm{j}=1, \ldots, \mathrm{n}
$$


- Calculate the nth root of $\mathrm{Mi}$

$$
\mathrm{W}_{i}^{*}=\sqrt[n]{M_{1}}, \mathrm{i}=1, \ldots, \mathrm{n}
$$

- Once done, obtain the following vector:

$$
\mathrm{W}^{*}=\left[\mathrm{W}_{1}^{*}, \mathrm{~W}_{2}^{*}, \ldots, \mathrm{W}_{n}^{*}\right]^{T}
$$

- Normalize the vector $\mathrm{W}^{*}$

$$
\mathrm{W}_{i}=\frac{\mathrm{W}_{i}^{*}}{\sum_{j=1}^{n} W_{j}^{*}}, i=1, \ldots, \mathrm{n}
$$

- The eigenvector of the judgment matrix A, that is:

$$
\mathrm{W}=\left[\mathrm{W}_{1}, \mathrm{~W}_{2}, \ldots, \mathrm{W}_{n}\right]^{T} \square
$$

Step 5: Calculate the importance factor of the load units for the whole system.

The importance factor of the load $\mathrm{W}_{\mathrm{ij}}$ for the whole system can be calculated from the equation (8).

$$
\mathrm{W}_{\mathrm{ij}}=\mathrm{W}_{\mathrm{LCi}} \mathrm{x} \mathrm{W}_{\mathrm{Lj}} \quad \mathrm{L}_{\mathrm{j}} \in \mathrm{LC}_{\mathrm{i}}
$$

Where: $\mathrm{L}_{\mathrm{j}} \in \mathrm{LC}_{\mathrm{i}}$ it means the $\mathrm{L}_{\mathrm{j}}$ load is located in the LCi Load Center.

\subsection{Primary and secondary frequency control}

The process of frequency adjustment in the event of generator outage in the electrical system consists of stages: the primary frequency control, the secondary frequency control. If after adjusting the secondary frequency control, the frequency has not yet been restored to the permissible value, it is required to load shedding to restore the frequency to the permissible value.

The process of the primary and secondary frequency control was shown in Figure 1.

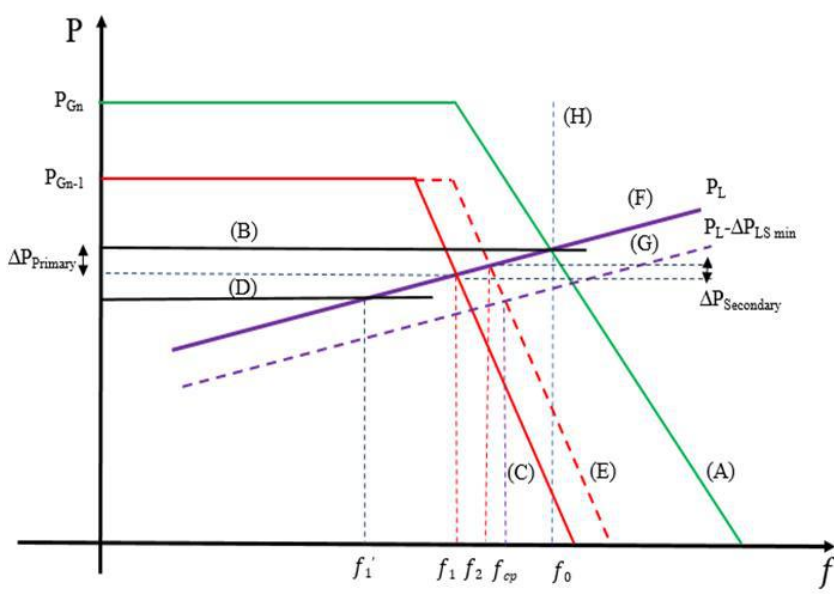

Fig. 1: The relationship between frequency deviation and output power deviation.

\subsection{The Artificial Neural Network training algorithms (ANN)}

There are 4 recommended ANN training algorithms in the identification problem: Lenvenberg-Marquardt, Bayesian, Scaled Conjugate Gradient and Resillient Backpropagation. In this paper, the 4 above algorithms are used to train ANN network to compare with each other and choose the most optimal algorithm.

Lenvenberg - Marquardt (trainlm) training algorithm: Trainlm is an ANN network training function that updates the weights and threshold values according to the Levenberg-Marquardt optimization algorithm. Trainlm is the fastest backpropagation algorithm compared to other algorithms and is of great choice [8].

Bayesian (trainbr) training algorithm: Trainbr is an ANN training function that allows updating weight and threshold values. It minimizes the combination of squaring and weighting errors, and then determines the correct combination to create a good generality neural network. This process is known as Bayes rule [9].

Scaled Conjugate Gradient (trainscg) training algorithm: Trainscg is an ANN network training function, which updates the weights and threshold values according to the federation method [10].

The training algorithm Resillient backpropagation (trainrp): Trainrp is an ANN network training function that updates the weights and threshold values according to the backpropagation algorithm [11].

\subsection{The proposed method}

When there is a generator outage in the power system, the SCADA system will collect data of the power system parameters. In the case that after the primary frequency control and secondary frequency control are performed but the frequency has not yet recovered to its allowable value, this data will be included in the data set to train the Artificial Neural Network (ANN). In this case, the minimum amount of shedding capacity is calculated. Then, the distribution of load shedding power at the load buses is done based on AHP algorithm. Here, the AHP algorithm supports in calculating the load importance coefficient. Loads with a small importance factor will be given priority to shedding large amounts of capacity and vice versa.

Flowchart of the proposed load shedding method is shown in Figure 2. 


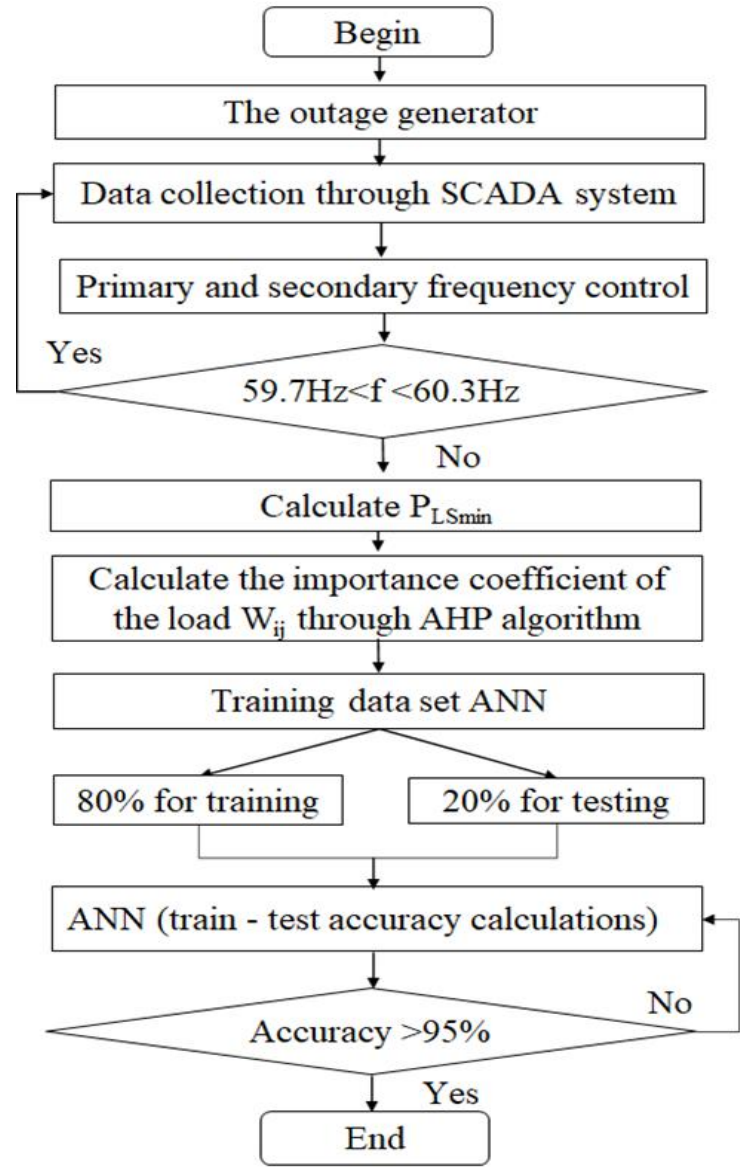

Fig. 2: Flowchart of the proposed load shedding method

\section{CASE STUDIES}

The proposed method is tested on the IEEE 37 bus 9generators electrical system [12]. The single line diagram of the system is shown in Figure 3. The generator at Bus31 is considered the Slack Bus.

From the single diagram of the electrical system, build a model of the hierarchy between the load centers and the loads in the load center. The results of building the model hierarchy are presented in Figure 4.
Next, construct judgment matrices that show the importance of the load centers to each other and the importance of the loads in the load center. Construction results are presented from Table 1 to Table 5 .

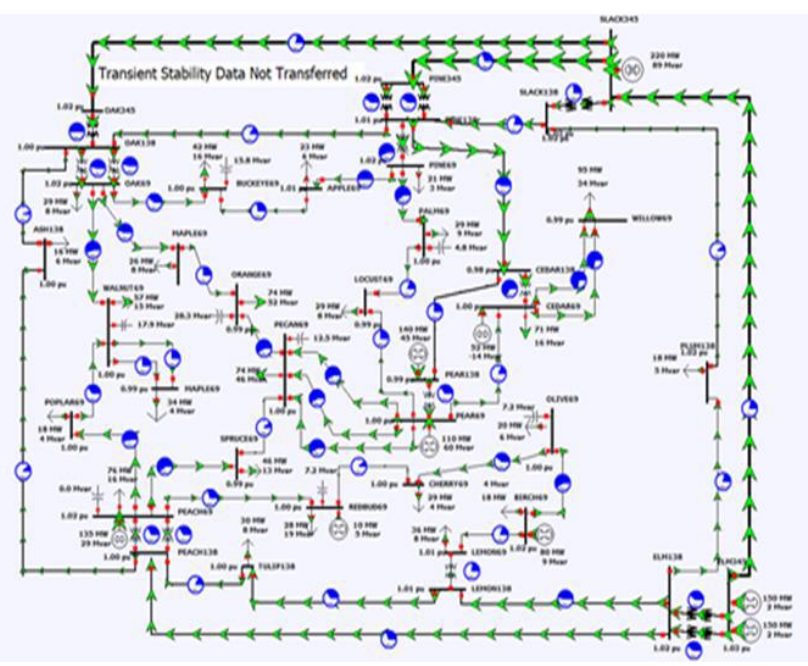

Fig. 3: The IEEE 37 bus 9 generators test system

\subsection{Calculate the importance factor of the load based on the AHP algorithm}

Table 1. The judgment matrix of load center $L C_{i}$

\begin{tabular}{|c|c|c|c|c|}
\hline $\mathbf{P I}$ & $\mathbf{L C}_{\mathbf{1}}$ & $\mathbf{L C}_{\mathbf{2}}$ & $\mathbf{L C}_{\mathbf{3}}$ & $\mathbf{L C}_{\mathbf{4}}$ \\
\hline $\mathrm{LC}_{1}$ & $1 / 1$ & $1 / 3$ & $1 / 1$ & $1 / 1$ \\
\hline $\mathrm{LC}_{2}$ & $3 / 1$ & $1 / 1$ & $1 / 1$ & $3 / 1$ \\
\hline $\mathrm{LC}_{3}$ & $1 / 1$ & $1 / 1$ & $1 / 1$ & $1 / 2$ \\
\hline $\mathrm{LC}_{4}$ & $1 / 1$ & $1 / 3$ & $2 / 1$ & $1 / 1$ \\
\hline
\end{tabular}

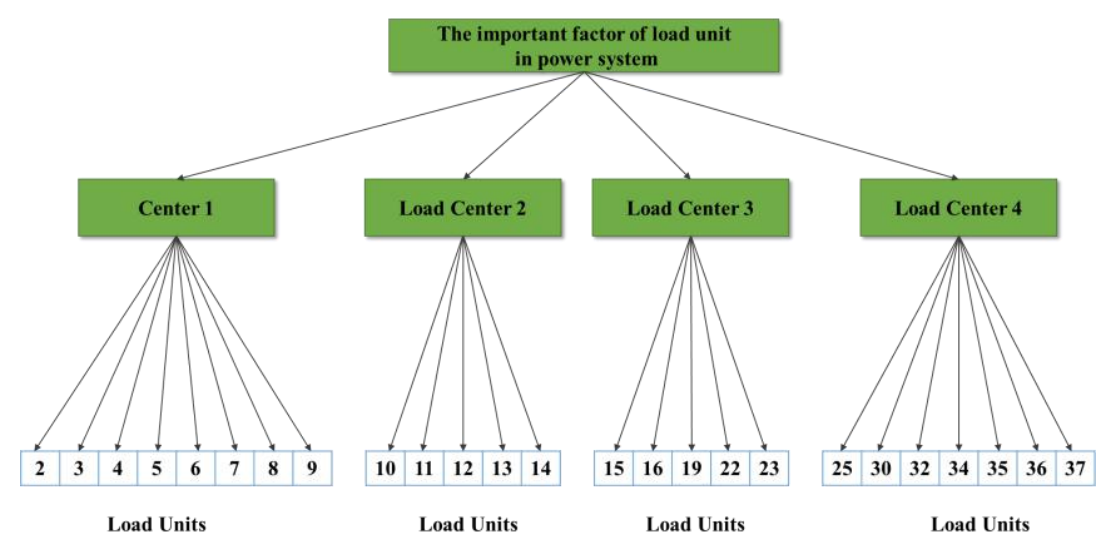

Fig. 4: AHP model for load centers and load units in IEEE 37 bus 9 generator 
Table 2. The judgment matrix of load $L_{j}$ at $L C_{l}$

\begin{tabular}{|l|l|l|l|l|l|l|l|l|}
\hline & $\mathbf{L}_{\mathbf{2}}$ & $\mathbf{L}_{\mathbf{3}}$ & $\mathbf{L}_{\mathbf{4}}$ & $\mathbf{L}_{\mathbf{5}}$ & $\mathbf{L}_{\mathbf{6}}$ & $\mathbf{L}_{7}$ & $\mathbf{L}_{\mathbf{8}}$ & $\mathbf{L} \mathbf{9}$ \\
\hline $\mathbf{L}_{\mathbf{2}}$ & $1 / 1$ & $1 / 1$ & $1 / 1$ & $1 / 3$ & $1 / 2$ & $1 / 3$ & $1 / 2$ & $1 / 2$ \\
\hline $\mathbf{L}_{\mathbf{3}}$ & $1 / 1$ & $1 / 1$ & $3 / 1$ & $1 / 1$ & $2 / 1$ & $1 / 1$ & $2 / 1$ & $1 / 1$ \\
\hline $\mathbf{L}_{\mathbf{4}}$ & $1 / 1$ & $1 / 3$ & $1 / 1$ & $1 / 2$ & $1 / 1$ & $1 / 2$ & $1 / 1$ & $2 / 1$ \\
\hline $\mathbf{L}_{\mathbf{5}}$ & $3 / 1$ & $1 / 1$ & $2 / 1$ & $1 / 1$ & $1 / 3$ & $1 / 3$ & $1 / 1$ & $1 / 3$ \\
\hline $\mathbf{L}_{\mathbf{6}}$ & $2 / 1$ & $1 / 2$ & $1 / 1$ & $3 / 1$ & $1 / 1$ & $1 / 1$ & $3 / 1$ & $1 / 3$ \\
\hline $\mathbf{L}_{7}$ & $3 / 1$ & $1 / 1$ & $2 / 1$ & $3 / 1$ & $1 / 1$ & $1 / 1$ & $1 / 2$ & $1 / 1$ \\
\hline $\mathbf{L}_{\mathbf{8}}$ & $2 / 1$ & $1 / 2$ & $1 / 1$ & $1 / 1$ & $1 / 3$ & $2 / 1$ & $1 / 1$ & $1 / 2$ \\
\hline $\mathbf{L} \mathbf{9}$ & $2 / 1$ & $1 / 1$ & $1 / 2$ & $3 / 1$ & $3 / 1$ & $1 / 1$ & $2 / 1$ & $1 / 1$ \\
\hline
\end{tabular}

Table 3. The judgment matrix of load $L_{j}$ at $L C_{2}$

\begin{tabular}{|l|c|c|c|c|c|}
\hline & $\mathbf{L}_{10}$ & $\mathbf{L}_{11}$ & $\mathbf{L}_{12}$ & $\mathbf{L}_{13}$ & $\mathbf{L}_{14}$ \\
\hline $\mathbf{L}_{10}$ & $1 / 1$ & $1 / 1$ & $1 / 1$ & $1 / 3$ & $1 / 2$ \\
\hline $\mathbf{L}_{11}$ & $1 / 1$ & $1 / 1$ & $3 / 1$ & $1 / 1$ & $1 / 1$ \\
\hline $\mathbf{L}_{12}$ & $1 / 1$ & $1 / 3$ & $1 / 1$ & $1 / 2$ & $2 / 1$ \\
\hline $\mathbf{L}_{13}$ & $3 / 1$ & $1 / 1$ & $2 / 1$ & $1 / 1$ & $1 / 3$ \\
\hline $\mathbf{L}_{14}$ & $2 / 1$ & $1 / 1$ & $1 / 2$ & $3 / 1$ & $1 / 1$ \\
\hline
\end{tabular}

Table 4. The judgment matrix of load $\mathrm{L}_{j}$ at $\mathrm{LC}_{3}$

\begin{tabular}{|l|c|c|c|c|c|}
\hline & $\mathbf{L}_{15}$ & $\mathbf{L} 16$ & $\mathbf{L} 19$ & $\mathbf{L}_{22}$ & $\mathbf{L} 23$ \\
\hline $\mathbf{L}_{15}$ & $1 / 1$ & $1 / 2$ & $1 / 1$ & $1 / 1$ & $1 / 2$ \\
\hline $\mathbf{L}_{16}$ & $2 / 1$ & $1 / 1$ & $3 / 1$ & $1 / 3$ & $1 / 1$ \\
\hline $\mathbf{L}_{19}$ & $1 / 1$ & $1 / 3$ & $1 / 1$ & $1 / 2$ & $2 / 1$ \\
\hline $\mathbf{L}_{22}$ & $1 / 1$ & $3 / 1$ & $2 / 1$ & $1 / 1$ & $1 / 3$ \\
\hline $\mathbf{L}_{23}$ & $2 / 1$ & $1 / 1$ & $1 / 2$ & $3 / 1$ & $1 / 1$ \\
\hline
\end{tabular}

Table 5. The judgment matrix of load $L_{j}$ at $L C_{4}$

\begin{tabular}{|l|l|l|l|l|l|l|l|}
\hline & $\mathbf{L} 25$ & $\mathbf{L} 30$ & $\mathbf{L} 32$ & $\mathbf{L} 34$ & $\mathbf{L} 35$ & $\mathbf{L} 36$ & $\mathbf{L} 37$ \\
\hline $\mathbf{L}_{25}$ & $1 / 1$ & $1 / 1$ & $1 / 1$ & $1 / 3$ & $1 / 2$ & $1 / 3$ & $1 / 2$ \\
\hline $\mathbf{L}_{30}$ & $1 / 1$ & $1 / 1$ & $3 / 1$ & $1 / 1$ & $1 / 1$ & $1 / 1$ & $1 / 1$ \\
\hline $\mathbf{L}_{32}$ & $1 / 1$ & $1 / 3$ & $1 / 1$ & $1 / 2$ & $2 / 1$ & $1 / 2$ & $2 / 1$ \\
\hline $\mathbf{L}_{34}$ & $3 / 1$ & $1 / 1$ & $2 / 1$ & $1 / 1$ & $1 / 3$ & $1 / 3$ & $1 / 1$ \\
\hline $\mathbf{L}_{35}$ & $2 / 1$ & $1 / 1$ & $1 / 2$ & $3 / 1$ & $1 / 1$ & $1 / 1$ & $3 / 1$ \\
\hline $\mathbf{L}_{36}$ & $3 / 1$ & $1 / 1$ & $2 / 1$ & $3 / 1$ & $1 / 1$ & $1 / 1$ & $1 / 2$ \\
\hline $\mathbf{L} 37$ & $2 / 1$ & $1 / 1$ & $1 / 2$ & $1 / 1$ & $1 / 3$ & $2 / 1$ & $1 / 1$ \\
\hline
\end{tabular}

Apply AHP algorithm presented in 2.1 section to calculate the importance factor of the load. Parameter values of the load and the results of calculation of the importance factor of the load are presented in Table 6.

\subsection{Minimum load-shedding calculation}

Calculating the minimum load shedding capacity $\mathrm{P}_{\mathrm{LS} \text { min }}$ ensures restoration of electricity system frequency to the allowable value, helps to reduce the least economic damage to electricity consumers. In a power system with $n$ generators, when a generator outage, the adjustment of the primary frequency of the remaining (n-1) generator [13, $14]$ is made with the adjustment of the power according to the following equation:

$\sum_{i=1}^{n-1} \Delta P_{\text {Primary control }}=\sum_{i=1}^{n-1} \frac{-P_{G_{n, i}}}{R_{i}} \cdot \frac{\Delta f_{1}}{f_{0}}$

Where, $\Delta P_{\text {Primary control }}$ is the primary control power of the i generator; $P_{G_{n, i}}$ is the rated power of the i generator; $\Delta f_{1}=f_{1}-f_{0}$ is the frequency attenuation; $\mathrm{f}_{\mathrm{n}}$ is the rated frequency of the power system.

When the generator outage, the difference between the generation power and the load power causes the frequency difference, in particular, to be decreased. The amount of power of the frequency-dependent load reduces the amount of $\Delta \mathrm{P}_{\mathrm{D}}$ [15]. The relationship between the load power variations with frequency variation is determined by the equation:

$\Delta P_{D}=-\frac{\Delta f}{f_{n}} \cdot P_{L} \cdot D$

Where, $\mathrm{P}_{\mathrm{L}}$ is the active power of the system's load, $\Delta \mathrm{P}_{\mathrm{D}}$ is the change of load power according to frequency change, $\mathrm{D}$ is the percentage characteristic of the change of load according to the percentage change of frequency [15], D value from $1 \%$ to $2 \%$ and experimentally determined in the power system. For example, a value of $\mathrm{D}=2 \%$ means that a $1 \%$ change in frequency will cause a $2 \%$ change in load.

Table 6. The values of the loads and the importance factor of the load are calculated by AHP

\begin{tabular}{|c|c|c|c|c|c|c|}
\hline $\begin{array}{c}\text { Load } \\
\text { cente } \\
\mathbf{r}\end{array}$ & $\mathbf{W}_{\mathbf{L C i}}$ & $\begin{array}{l}\text { Load } \\
\text { Bus t }\end{array}$ & $\begin{array}{c}\text { Cost } \\
\mathrm{C}_{\mathbf{m i}}(\$ / \\
\mathbf{k W})\end{array}$ & $\begin{array}{l}W_{L j} \\
\text { (load } \\
\text { unit) }\end{array}$ & $\begin{array}{c}\text { The } \\
\text { impor } \\
t \text { tanct } \\
\text { factor } \\
W_{i j}\end{array}$ & $\begin{array}{c}\mathbf{P}_{\mathrm{LSi}} \\
(\mathbf{M W})\end{array}$ \\
\hline $\mathrm{LC} 1$ & 0.18 & $\mathrm{~L}_{2}$ & 220 & 0.07 & 0.0126 & 1.59 \\
\hline $\mathrm{LC} 1$ & 0.18 & $\mathrm{~L}_{3}$ & 200 & 0.16 & 0.0293 & 0.68 \\
\hline $\mathrm{LC} 1$ & 0.18 & $\mathrm{~L}_{4}$ & 280 & 0.10 & 0.0172 & 1.16 \\
\hline
\end{tabular}




\begin{tabular}{|l|c|c|c|c|c|c|}
\hline LC1 & 0.18 & $\mathrm{~L}_{5}$ & 200 & 0.10 & 0.0178 & 1.12 \\
\hline LC1 & 0.18 & $\mathrm{~L}_{6}$ & 250 & 0.14 & 0.0246 & 0.81 \\
\hline LC1 & 0.18 & $\mathrm{~L}_{7}$ & 300 & 0.16 & 0.0283 & 0.71 \\
\hline LC1 & 0.18 & $\mathrm{~L}_{8}$ & 280 & 0.10 & 0.0187 & 1.07 \\
\hline LC1 & 0.18 & $\mathrm{~L}_{9}$ & 280 & 0.17 & 0.0308 & 0.65 \\
\hline LC2 & 0.41 & $\mathrm{~L}_{10}$ & 245 & 0.07 & 0.0556 & 0.36 \\
\hline LC2 & 0.41 & $\mathrm{~L}_{11}$ & 280 & 0.14 & 0.0991 & 0.2 \\
\hline LC2 & 0.41 & $\mathrm{~L}_{12}$ & 220 & 0.24 & 0.0638 & 0.31 \\
\hline LC2 & 0.41 & $\mathrm{~L}_{13}$ & 280 & 0.16 & 0.0913 & 0.22 \\
\hline LC2 & 0.41 & $\mathrm{~L}_{14}$ & 220 & 0.22 & 0.0991 & 0.2 \\
\hline LC3 & 0.20 & $\mathrm{~L}_{15}$ & 280 & 0.15 & 0.0295 & 0.68 \\
\hline LC3 & 0.20 & $\mathrm{~L}_{16}$ & 220 & 0.23 & 0.0447 & 0.45 \\
\hline LC3 & 0.20 & $\mathrm{~L}_{19}$ & 245 & 0.16 & 0.0312 & 0.64 \\
\hline LC3 & 0.20 & $\mathrm{~L}_{22}$ & 220 & 0.23 & 0.0447 & 0.45 \\
\hline LC3 & 0.20 & $\mathrm{~L}_{23}$ & 280 & 0.24 & 0.0484 & 0.41 \\
\hline LC4 & 0.21 & $\mathrm{~L}_{25}$ & 280 & 0.08 & 0.0176 & 1.13 \\
\hline LC4 & 0.21 & $\mathrm{~L}_{30}$ & 220 & 0.16 & 0.0344 & 0.58 \\
\hline LC4 & 0.21 & $\mathrm{~L}_{32}$ & 250 & 0.12 & 0.0252 & 0.79 \\
\hline LC4 & 0.21 & $\mathrm{~L}_{34}$ & 300 & 0.13 & 0.0278 & 0.72 \\
\hline LC4 & 0.21 & $\mathrm{~L}_{35}$ & 245 & 0.19 & 0.0403 & 0.5 \\
\hline LC4 & 0.21 & $\mathrm{~L}_{36}$ & 280 & 0.19 & 0.0403 & 0.5 \\
\hline LC4 & 0.21 & $\mathrm{~L}_{37}$ & 300 & 0.13 & 0.0278 & 0.72 \\
\hline & & Total $(\mathbf{M W})$ & & & $\mathbf{1 6 . 6 4}$ \\
\hline
\end{tabular}

From (14) infer: $\quad \Delta P_{L}=\frac{-\Delta f_{1}}{f_{n}} \cdot \beta$

In the case of the considering secondary control power, the new power balance equation with the new frequency value $\mathrm{f} 2$, the equation (11) becomes:

$P_{L}-\Delta P_{D}=\sum_{i=1}^{n-1} P_{G_{i}}+\sum_{i=1}^{n-1} \Delta P_{\text {Primary control }}+\Delta P_{\text {Secondary control max }}$

Where, $\Delta P_{\text {Secondary control max }}$ is the maximum amount of secondary control power supplied to the power system.

$\Delta P_{\text {Secondary control max }}=P_{G m, j}-\Delta P_{\text {Primary control, } \mathrm{j}}$

After performing the secondary control process but the system frequency has not yet been restored to the allowable value, then load shedding is required to restore the frequency, the minimum amount of load shedding power $\mathrm{P}_{\mathrm{LSmin}}$ is calculated by the following equation:

$$
\begin{gathered}
P_{L}-\Delta P_{D}-P_{L S \text { min }}=\sum_{i=1}^{n-1} P_{G_{i}}+\sum_{i=1}^{n-1} \Delta P_{\text {Primary control }}+\Delta P_{\text {Secondary control max }} \\
\Delta P_{L S \text { min }}=P_{L}-\Delta P_{D}-\sum_{i=1}^{n-1} P_{G_{i}}-\sum_{i=1}^{n-1} \Delta P_{\text {Primary control }}-\Delta P_{\text {Secondary control max }} \\
\Delta P_{L S \text { min }}=P_{L}-\sum_{i=1}^{n-1} P_{G_{i}}+\frac{\Delta f_{c p}}{f_{0}} \cdot P_{L} \cdot D+\sum_{i=1}^{n-1} \frac{P_{G_{n i .}}}{R_{i}} \cdot \frac{\Delta f_{c p}}{f_{0}}-\Delta P_{\text {Secondary control max }}
\end{gathered}
$$

Equation (15) is abbreviated according to the following equation:

$$
\Delta P_{L S \text { min }}=\Delta P_{L}+\frac{\Delta f_{c p}}{f_{0}} \cdot \beta-\Delta P_{\text {Secondary control max }}
$$

The case study, the generator BLT138 (Bus 53) is disconnected from the grid. In the IEEE 37 bus 9-generator electrical system diagram, the SLACK 345 (SLACK Bus) is selected as the secondary frequency control generator. The amount of the secondary control power is $10.72 \mathrm{MW}$. The primary control power values of each generator turbine are shown in Table 7.

Table 7. Value of parameters and primary control power of the generators

\begin{tabular}{|c|l|l|c|c|c|c|}
\hline No & Gen & $\mathbf{P}_{\mathbf{G}(\mathbf{M W})}$ & $\mathbf{P}_{\mathbf{G} \text { (pu) }}$ & $\mathbf{R}$ & $\Delta P_{\mathrm{Pri}}$ & $\frac{P_{G, n}}{R}$ \\
\hline 1 & $\begin{array}{l}\text { WEBER6 } \\
9\end{array}$ & 31.5 & 0.315 & 0.05 & $\begin{array}{c}0.03 \\
5\end{array}$ & 7 \\
\hline 2 & JO345\#1 & 135 & 1.35 & 0.05 & 0.15 & 30 \\
\hline 3 & JO345\#2 & 135 & 1.35 & 0.05 & 0.15 & 30 \\
\hline 4 & $\begin{array}{l}\text { SLACK34 } \\
5\end{array}$ & 187.28 & $\begin{array}{c}1.872 \\
8\end{array}$ & 0.05 & 0.22 & 44 \\
\hline
\end{tabular}




\begin{tabular}{|c|c|c|c|c|c|c|}
\hline 5 & LAUF69 & 135 & 1.35 & 0.05 & 0.15 & 30 \\
\hline 6 & ВOB69 & 46 & 0.46 & 0.05 & $\begin{array}{c}0.05 \\
2\end{array}$ & 10.4 \\
\hline 7 & ROGER69 & 72 & 0.72 & 0.05 & 0.08 & 16 \\
\hline 8 & BLT138 & 0 & 0 & 0.05 & 0 & 0 \\
\hline 9 & BLT69 & 31.5 & 0.315 & 0.05 & $\begin{array}{c}0.03 \\
5\end{array}$ & 7 \\
\hline & Total & 831.78 & $\begin{array}{l}8.317 \\
8\end{array}$ & & $\begin{array}{l}0.94 \\
7\end{array}$ & $\begin{array}{l}189 . \\
4\end{array}$ \\
\hline
\end{tabular}

The construction of the data set is performed as follows: PowerWorld GSO 19 software is used for off-line simulation to collect data for neural network training to distribute the load shedding control strategy when the generator outage occurred. In each case, after performing the processes of primary frequency and secondary frequency control, the electrical system will perform load shedding when the frequency falls below the permitted threshold $59.7 \mathrm{~Hz}$. The amount of load shedding capacity is calculated and the distribution of load shedding capacity at the load buses is done based on AHP algorithm.

For the construction of the training data set will be collected by changing the load from $60 \%$ to $100 \%$ of the maximum load, and changing the location of the faulty generator. During the simulation, the cases that have to shedding the load are put into a data set to train the neural network. The results were a data set consisting of 122 samples. During neural network training, the data set is divided into $80 \%$ data for training and $20 \%$ data for testing. Data were standardized before training.

The neural network structure consists of 3 layers: input layer, hidden layer and output layer. The total number of input variables is 164 variables (including: $9 \Delta \mathrm{P}_{\mathrm{G}}$ variables, $25 \Delta \mathrm{P}_{\text {Load }}$ variables and $56 \Delta \mathrm{P}_{\text {Branch }}$ variables, 37 $\Delta \mathrm{f}_{\text {Bus }}$ variables, $37 \Delta \mathrm{V}_{\text {Bus }}$ variables). The amount of load shedding at the load buses ( 25 variables) are the output signals corresponding to the case of generator outage. ANN configuration is shown in Figure 5.

The ANN is trained with the use of Back Propagation Neural Network (BPNN) with 4 training algorithms: Lenvenberg-Marquardt (trainlm), Bayesian (trainbr), Scaled Conjugate Gradient (trainscg), Resillient Backpropagation (trainrp) to compare the effectiveness of training methods. The results of the training accuracy and the test accuracy of the training methods are presented in Table 8 and Figure 6.

\subsection{Building learning patterns and training neural} networks

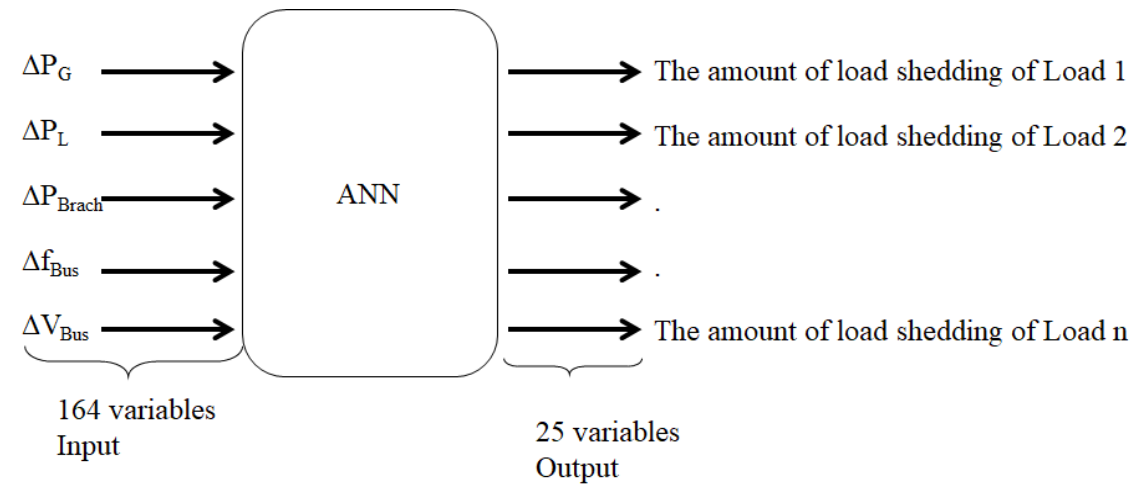

Fig. 5: ANN configuration 
Table 8. Training and test accuracy of Artificial Neural Network training methods

\begin{tabular}{|l|l|c|l|c|}
\hline $\begin{array}{l}\text { Training algorithm } \\
\text { for ANN }\end{array}$ & $\begin{array}{l}\text { Lenvenberg-Marquardt } \\
\text { (trainlm) }\end{array}$ & Bayesian (trainbr) & $\begin{array}{l}\text { Scaled Conjugate } \\
\text { Gradient } \\
\text { (trainscg) }\end{array}$ & $\begin{array}{c}\text { Resillient Backpropagation } \\
\text { (trainrp) }\end{array}$ \\
\hline $\begin{array}{l}\text { Training accuracy } \\
(\%)\end{array}$ & 0 & 99.74 & 97.4 & 97.92 \\
\hline Test accuracy (\%) & 0 & 98.51 & 98.51 & 98.51 \\
\hline $\begin{array}{l}\text { Training algorithm } \\
\text { for ANN }\end{array}$ & $\begin{array}{l}\text { Lenvenberg-Marquardt } \\
\text { (trainlm) }\end{array}$ & Bayesian (trainbr) & $\begin{array}{l}\text { Scaled Conjugate } \\
\text { Gradient } \\
\text { (trainscg) }\end{array}$ & $\begin{array}{c}\text { Resillient Backpropagation } \\
\text { (trainrp) }\end{array}$ \\
\hline
\end{tabular}

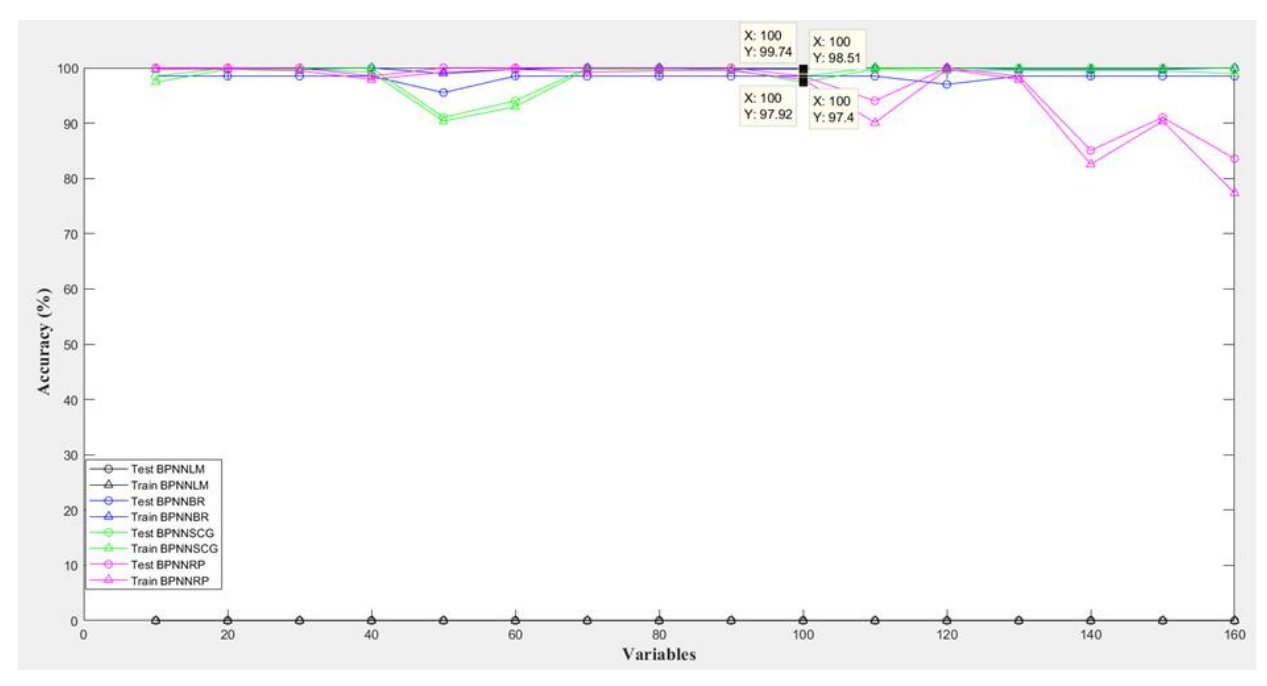

Fig. 6: The training and testing accuracy comparison of the ANN training algorithms

From the data results Figure 6 shows that in the case of identifying the load shedding strategy, the training method using the neural network with the Bayesian training algorithm has the highest accuracy. In addition, as the number of input variables increases, the accuracy increases and reaches the highest precision value when reaching 100 variables with a training accuracy of $99.74 \%$ and test accuracy of $98.51 \%$.

Comparing the proposed load shedding method (ANNAHP) with the load shedding method using the underfrequency load shedding relay (UFLS) when done with the same amount of shedding capacity is $16.64 \mathrm{MW}$. Here, the method of load shedding using neural network combined with AHP algorithm has a load shedding time of $300 \mathrm{~ms}$ after the generator failure occurs. The method of load shedding using the load shedding relay UFLS has the time of cut the load after the frequency drops below the threshold value. The result of frequency simulation and the economic losses associated with load shedding are presented in Figure 7 and Table 9.

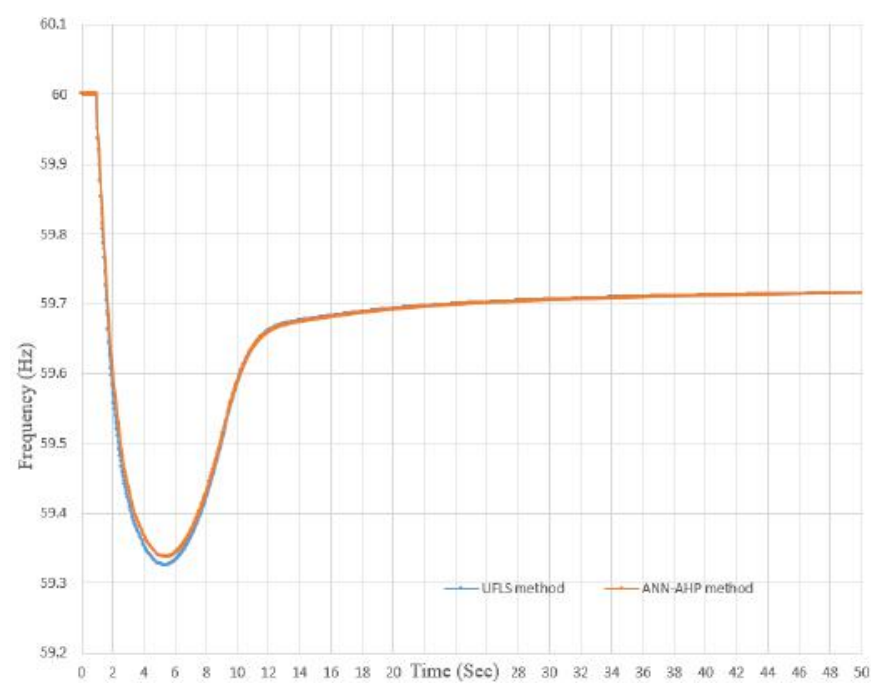

Fig. 7: The frequency of the system when applying the traditional and the proposed load shedding method 
Table 9. Comparing economic losses of load shedding based on AHP algorithm and UFLS

\begin{tabular}{|l|c|c|}
\hline Load shedding Methods & ANN-AHP & UFLS \\
\hline Load shedding (MW) & 16.64 & 16.64 \\
\hline $\begin{array}{l}\text { Recovery frequency value } \\
(\mathrm{Hz})\end{array}$ & 59.7 & 59.7 \\
\hline $\begin{array}{l}\text { Lowest value of frequency } \\
\text { response (Hz) }\end{array}$ & 59.35 & 59.31 \\
\hline $\begin{array}{l}\text { Time of recovery } \\
\text { frequency }(\mathrm{s})\end{array}$ & 44 & 44 \\
\hline $\begin{array}{l}\text { Economic damage } \\
\sum \mathrm{P}_{\mathrm{LSi}} \mathrm{C}_{\mathrm{mi}}\left(\mathrm{x} 10^{3}\right)(\$)\end{array}$ & 4245.7 & 4351.69 \\
\hline
\end{tabular}

Figure 7 shows that the load shedding method based on ANN - AHP algorithm and load shedding based on UFLS have the recovered frequency value to the allowable value. Both methods have the same set state frequency value. The reason is that they have the same load shedding capacity. However, the frequency response quality of the UFLS method is lower than the AHP method.

The lowest value of frequency response of ANN-AHP method is always higher and better than UFLS method. The reason is that the ANN-AHP method has very fast ANN processing times, so a decision to quickly implement the load shedding control strategy. Meanwhile, the UFLS method must wait for the frequency to drop below the set threshold of the UFLS relay to impact load shedding. That has slowed down the decision of load shedding and the frequency response value is not better than the ANN-AHP method.

In addition, despite having the same amount of load shedding capacity, the method of load shedding based on ANN-AHP has lower damage value compared to UFLS method. This is because the AHP algorithm ranks the loads in order of importance. Loads with low importance will be shed with more power priority. This has contributed to reduce damage caused by power outages.

\section{CONCLUSION}

The load shedding ranking and the load importance factor calculation based on the AHP algorithm have contributed to reducing the damage caused by load shedding. The application of ANN network to quickly identify the load shedding control strategy has contributed to improving the frequency response quality of the load shedding solution. The effectiveness of the proposed method has been demonstrated on the 9 generator 37-bus system.

\section{ACKNOWLEDGEMENTS}

This work belongs to the project in 2020 funded by Ho Chi Minh City University of Technology and Education, Vietnam.

\section{REFERENCES}

[1] Yinliang $\mathrm{Xu}$, Wenxin Liu and Jun Gong, "Stable MultiAgent-Based Load Shedding Algorithm for Power Systems", IEEE Transactions On Power Systems, Vol. 26, No. 4, November 2011.

[2] Xin Xu, Hengxu Zhang, Changgang Li, Yutian Liu, Wei Li, Vladimir Terzija, "Optimization of the Event-Driven Emergency Load-Shedding Considering Transient Security and Stability Constraints", IEEE Transactions on Power Systems, Vol. 32, No. 4, July .

[3] Fang Shi, Hengxu Zhang, Yongji Cao, Huadong Sun, Yun Chai, "Enhancing Event-Driven Load Shedding by Corrective Switching With Transient Security and Overload Constraints", IEEE Access, Vol. 7, July 2019.

[4] Ahmed N. Al-Masri ; Mohd Zainal Abidin Ab Kadir ; Ali Saadon Al-Ogaili ; Yap Hoon, "Development of Adaptive Artificial Neural Network Security Assessment Schema for Malaysian Power Grids", IEEE Access, Vol. 7, December 2019.

[5] Ankur Kumar, Ritula Thakur, "A Fuzzy Logic Based Load Shedding Technique for Operation of DG in Islanding Mode", IEEE International Conference on Computational Intelligence and Computing Research (ICCIC), December 2017.

[6] M. K. Gray ; W. G. Morsi, "Application of PSO and fuzzy logic for underfrequency load shedding", IEEE Electrical Power \& Energy Conference, Aug. 2013.

[7] T.L. Saaty, The Analytic Hierarchy Process. McGraw-Hill, New York, 1980.

[8] Wei Bengang, Wu Xinye, Yao Zhoufei and Huang Hua, "A method of optimized neural network by L-M algorithm to transformer winding hot spot temperature forecasting," 2017 IEEE Electrical Insulation Conference (EIC), Baltimore, MD, 2017, pp. 87-91, doi: 10.1109/EIC.2017.8004603.

[9] Walker H. LandJr, J. David Schaffer. Bayesian Probabilistic Neural Network. The Art and Science of Machine Intelligence, 2019, pp 187-210.

[10] Walaa M. Khalaf, Mohammed Ali Tawfeeq, Kadhum AlMajdi. Edge Detection Using Scaled Conjugate Gradient Algorithm in Back Propagation Neural Network. Eng. \& Tech. Journal,Vol.32,Part (A), No.2, 2014, pp. 385-395.

[11] Chien-Sheng Chen, Szu-Lin Su, He-Nian Shou and WenHsiung Liu, "Resilient back-propagation neural network for approximation weighted geometric dilution of precision," 2010 3rd International Conference on Computer Science and Information Technology, Chengdu, 2010, pp. 53-58, doi: 10.1109/ICCSIT.2010.5563546. 
[12] J. Duncan Glover, Mulukutla S. Sarma, Thomas J. Overbye, "Power System Analysis and Design", Sixth Edition, Cengage Learning, pp. 718, 2017.

[13] P. Kundur, Power System Stability and Control, McGrawHill, 1994.

[14] Sam Weckx, Reinhilde D'Hulst, Johan Driesen, "Primary and Secondary Frequency Support by a Multi-Agent Demand Control System", IEEE Transactions on Power Systems, Vol. 30, Issue: 3, pp. 1394 - 1404, 2015.

[15] A. J. Wood, et al., "Power Generation, Operation and Control," Third Edition, John Wiley \& Sons, Inc, pp. 473481, 2014.

[16] IEEE Standard. IEEE guide for the application of protective relays used for abnormal frequency load shedding and restoration. IEEE Std C37117-2007, p.41-43. 